\title{
The economic burden of uncontrolled asthma across Europe and the Asia-Pacific region: can we afford to not control asthma?
}

\author{
E.D. Bateman
}

A sthma is a treatable disease, yet in spite of considerable progress in knowledge and the availability of effective treatments, it continues to constitute a significant burden for health services and healthcare budgets and was ranked 25th amongst all causes of disabilityadjusted life years in adults and children in 2001 [1]. The Asthma Insight and Reality (AIR) surveys of persons living with asthma, performed in several regions of the world, provide a record of the chronic and often daily personal burden borne by those who have this disease and of the fact that a minority of patients receive appropriate controller therapy [2-4]. Equally surprising is the fact that, at the time of these surveys, performed first in Europe [2], the USA and Canada, and later in the Asia-Pacific region [4], the situation appeared to be only marginally better in countries with more advanced and comprehensive health systems and greater expenditure on health. The surveys revealed high levels of persistent symptoms, unscheduled visits to doctors (averaging almost five times per year in some countries), emergency room visits in up to one-third of patients, and hospitalisation for asthma in up to $30 \%$ of patients each year [2-4]. Findings like these point to the need for reappraisal of management guidelines and goals of treatment, and for ensuring that caregivers and patients are made aware of these goals, how they might be achieved, and of the benefits of optimal treatment.

Amongst the many reasons why treatment remains suboptimal are lack of recognition on the part of patients and caregivers of how poorly patients' asthma is being controlled, uncertainty about what can be achieved, and concerns about the cost and safety of treatment [2-5]. Some of these points are addressed in the articles in this issue of the European Respiratory Review; namely, the use of a validated self-administered measures to assess asthma control, and the potential economic benefit of achieving control of asthma [6-9].

The first of these issues is recognition of poor control and improving measures to assess control. Most current asthma guidelines emphasise that the goal of treatment is to achieve and maintain control of the disease [10]. However, they differ from one another in their approach to defining control. The Global Initiative for Asthma (GINA) treatment guideline provides a list of goals, and it is implied but not stated that control might be considered to be the successful achievement of all of these goals [10]. The French [11] and American Academy of Asthma, Allergy and Immunology documents [12], both published in 2005, adopt objective definitions, and like the Gaining Optimal Asthma ControL (GOAL) study [13], propose different levels of control based upon a composite of clinical end-points, such as "acceptable" control, "complete or total control" and "well controlled". In contrast with these, the latest British guideline advises against a rigid clinical definition of control, preferring to view as acceptable what the patient, in consultation with the caregiver, considers adequate [14]. However, regardless of what level is viewed as ideal or acceptable, there is the need for measurement an assessment of whether the target has been reached and is being maintained. This "treat to target" approach, to a numerical value, is a feature of the treatment of other chronic conditions, such as diabetes and hypertension, but has been lacking in the management of asthma. This realisation has prompted the development of a number of control measures, including the Asthma Control Test ${ }^{\mathrm{TM}}$ (ACT) [15], the Asthma Control Questionnaire (ACQ) [16, 17], and the Asthma Therapy Assessment Questionnaire (ATAQ) [18]. The ACT is a reliable validated self-administered measure comprising five items
AFFILIATIONS

University of Cape Town, Cape Town, South Africa.

CORRESPONDENCE

E. Bateman

Division of Pulmonology

Dept of Medicine

PO Box 34560

Groote Schuur 7937

Cape Town

South Africa

Fax: 27214066902

E-mail: ebateman@

uctgsh1.uct.ac.za 
relating to limitations to activities, shortness of breath, nighttime and early morning awakening, use of rescue medication and the patient's perception of control. Each question is scored between 1 and 5, and a maximum five-question score of 25 represents complete control of asthma over the past 4 weeks, scores of $\geqslant 20$, well-controlled asthma, and scores of 15-19 suggest that asthma is not well controlled. Scores $<15$ represent poor control. Treating to control involves identifying patients with values of $<20$, and commencing or increasing treatment to gain control. NATHAN et al. [15] have reported a negative predictive value for the ACT of $84.9 \%$, meaning that $84 \%$ of patients with an ACT score of $<20$ will be correctly categorised as not having well-controlled asthma. The test is relatively quick and easy to use, is available in more than 40 languages and can be accessed on the web (www.asthmacontrol.com).

Although the ACT did not form part of the assessment in the AIR surveys, the papers by VERVLOET et al. [6] and LAI et al. [7] in this issue of the European Respiratory Review, describe the ACT levels of asthma control derived from responses to questions in those surveys that were similar or the same as the five items of the ACT. Scored in this way, $52 \%$ of patients in European countries surveyed in 1999 and $41 \%$ of patients in the Asia-Pacific countries surveyed in 2000 had well-controlled asthma at the time of the assessment (that is, ACT values of $\geqslant 20$ ) and only 8 and 1\%, respectively, complete control (ACT score of 25) $[6,7]$. While this is encouraging, attention must be paid to those who were not controlled. A picture of the financial burden that these patients place upon healthcare resources compared with those that are controlled is provide by the four papers in this issue of the European Respiratory Review [6-9].

The first two articles detail the costs of the asthma morbidity and permit comparisons between countries in Europe and survey areas in the Asia-Pacific region $[8,9]$. Comparisons are limited by differences in methodology between the studies, and conclusions must be viewed as tentative. For example, the Asthma Insights and Reality in Europe (AIRE) study was a telephone survey and direct costs of drugs (which in different countries in Europe may constitute 15 to $75 \%$ of direct costs) were excluded. The Asthma Insights and Reality study in AsiaPacific (AIRIAP) questionnaire was administered by an interviewer, and the cost of drugs in different areas surveyed ranged between 10 and $75 \%$ of direct costs of managing asthma. Costs are also influenced by the source and pricing of medicines, the relative cost of physician visits and hospitalisation, and patterns of healthcare use, and even within the AsiaPacific region, striking differences are evident. However, some broad conclusions may be drawn. First, from the ACT assessment of control, fewer patients in the Asia-Pacific region were controlled (41 versus 52\% had a score of 20-25) [6, 7] and the direct cost per patient of managing asthma (excluding drug costs) was three times higher in Europe ( $€ 566$ versus $€ 187$ per patient) [6, 7]. However, relative to per capita healthcare expenditure and gross domestic product (GDP) in the AsiaPacific region even the lower figure is very high, averaging more than $300 \%$ of per capita healthcare costs and $13 \%$ of GDP, and in countries like China and Vietnam, this is equivalent to $>30 \%$ of GDP [9]. This burden is also evident in estimates of the total societal costs of asthma expressed as a percentage of per capita GDP. The mean percentage of total societal costs of asthma for this region was $16 \%$, and ranged from $2 \%$ of GDP to a staggering
$46 \%$ of GDP in poorer countries - an untenable situation [9]. Furthermore, common to both surveys was the fact that the highest expenditure was in patients with severe persistent symptoms, and that approximately half of the direct cost of managing these patients was the cost of unscheduled resource use (emergency visits to doctor and/or emergency room) and hospitalisation $[8,9]$. This was true in every country surveyed; even in those where, in theory, patients had unrestricted access to inhaled corticosteroids and other controller drugs.

What do these results tell us about the relation between expenditure and asthma control? First, the costs associated with controlled asthma are lower than those for managing uncontrolled asthma, the major difference being the cost of managing unexpected events. Clearly, this relationship might not be causal, but might reflect the fact that patients whose asthma is readily controlled require less medication and incur fewer costs. However, the results are consistent with results of prospective trials and initiatives that have aimed at increasing the use of controller treatment to achieve higher levels of control and avoiding costly exacerbations [19-22]. Thus, while some patients might be relatively refractory to controllers and require costly maintenance treatment without reaching satisfactory levels of control [13], the majority have the prospect of achieving control with doses of treatment that are affordable in most health systems, thereby reducing rather than increasing direct costs of treatment. Thus, both from the perspective of the patient and on economic grounds, one needs to question whether any society or health system can afford to not control asthma, or at least to make this the goal of asthma management. This approach might go some way toward improving the standard of practice for patients with asthma, reducing morbidity and potentially even reducing the direct and societal costs of caring for patients with this disease.

\section{REFERENCES}

1 World Health Report 2002. Reducing Risks, Promoting Healthy Life. Geneva, World Health Organisation, 2002; 68-76.

2 Rabe K, Vermeire P, Soriano J, Maier W. Clinical management of asthma in 1999: the Asthma Insights and Reality in Europe (AIRE) study. Eur Respir J 2000; 16: 802-807.

3 Lai CKW, de Guia TS, Kim Y-Y, et al. Asthma control in the Asia-Pacific region: the Asthma Insights and Reality in Asia-Pacific Study. J Allergy Clin Immunol 2003; 111: 263-268.

4 Rabe KF, Adachi M, Lai CK, et al. Worldwide severity and control of asthma in children and adults: the global asthma insights and reality surveys. J Allergy Clin Immunol 2004; 114: 40-47.

5 Masoli M, Fabian D, Holt S, Beasley R. Global Burden of Asthma. (Work commissioned by Global Initiative for Asthma/GINA), 2004. http://www.ginasthma.com/ ReportItem.asp? $11=2 \& 12=2 \&$ intId $=94$. Date last accessed: April 5, 2006.

6 Vervloet D, Williams AE, Lloyd A, Clark TJH. Costs of managing asthma as defined by a derived Asthma Control Test $^{\text {TM }}$ score in seven European countries. Eur Respir Rev 2006; 98: 17-23. 
7 Lai CKW, Kuo S-H, de Guia T, Lloyd A, Williams AE, Spencer MD. Asthma control and its direct healthcare costs: findings using a derived Asthma Control Test ${ }^{\mathrm{TM}}$ score in eight Asia-Pacific areas. Eur Respir Rev 2006; 98: 24-29.

8 Williams AE, Lloyd AC, Watson L, Rabe KF. Cost of scheduled and unscheduled asthma management in seven European Union countries. Eur Respir Rev 2006; 98: 4-9.

9 Lai CKW, Kim Y-Y, Kuo S-H, Spencer M, Williams AE on behalf of the Asthma Insights and Reality in Asia Pacific Steering Committee. Cost of asthma in the Asia-Pacific region. Eur Respir Rev 2006; 98: 10-16.

10 Global Strategy for Asthma Management and Prevention, Bethesda, MD, NIH publication No. 02-3659. Issued January, 1995. Updated 2005 from the 2004 document. Also available on www.ginasthma.org.

11 Roche N, Morel H, Martel P, Godard P. Clinical practice guidelines: medical follow-up of patients with asthma adults and adolescents. Resp Med 2005; 99: 793-815.

12 Li JT, Oppenheimer J, Bernstein IL, Nicklas RA, for the Joint Task Force Reviewer. Attaining optimal asthma control: a practice parameter. J Allergy Clin Immunol 2005; 116: S3-S22.

13 Bateman ED, Homer A, Boushey JB, et al. Can guidelinedefined asthma control be achieved? The Gaining Optimal Asthma ControL Study. Am J Respir Crit Care Med 2004; 170: 836-844.

14 British guidelines on the management of asthma. Pharmacological management. Thorax 2003; 58: Si17-Si28.
15 Nathan RA, Sorkness CA, Kosinski M, et al. Development of the asthma control test: a survey for assessing asthma control. J Allergy Clin Immunol 2004; 113: 59-65.

16 Juniper EF, O’Byrne PM, Guyatt GH, Ferrie PJ, King DR. Development and validation of a questionnaire to measure asthma control. Eur Respir J 1999; 14: 902-907.

17 Juniper EF, Bousquet J, Abetz L, Bateman ED, the GOAL Committee. Identifying "well-controlled" and not wellcontrolled" asthma using the Asthma Control Questionnaire. Resp Med 2006; 100: 616-621.

18 Vollmer WM, Markson LE, O'Connor E, et al. Association of asthma control with health care utilization and quality of life. Am J Respir Crit Care Med 1999; 160: 1647-1652.

19 Haahtela T, Laitinen LA. Asthma programme in Finland 1994-2004. Report of a Working Group. Clin Exp Allergy 1996; 26: Suppl. 1, 1-24.

20 Sullivan SD, Buxton M, Andersson LF, et al. Costeffectiveness analysis of early intervention with budesonide in mild persistent asthma. J Allergy Clin Immunol 2003; 122: $1229-1236$.

21 Lyseng-Williamson KA, Plosker GL. Inhaled salmeterol/ fluticasone propionate combination: a pharmacoeconomic review of its use in the management of asthma. Pharmacoeconomics 2003; 21: 951-989.

22 Sullivan SD, Weiss KB, Lynn $\mathrm{H}$, et al. The cost-effectiveness of an inner-city asthma intervention in children. J Allergy Clin Immunol 2002; 110: 576-581. 